\title{
Sodium Bicarbonate/Potassium Bicarbonate/Anhydrous Citric Acid
}

National Cancer Institute

\section{Source}

National Cancer Institute. Sodium Bicarbonate/Potassium Bicarbonate/Anhydrous Citric

Acid. NCl Thesaurus. Code C95200.

A combination preparation containing sodium bicarbonate, potassium bicarbonate, and anhydrous citric acid, with acid-neutralizing properties. This combination in water principally contains the antacids potassium citrate and sodium citrate, and is used for the relief of acid indigestion and heartburn. This combination does not contain aspirin, and therefore does not exert aspirin's analgesic or anti-inflammatory effects. 